Rabaska

Revue d'ethnologie de l'Amérique française

\title{
Centre franco-ontarien de folklore
}

\section{Joanne Gervais}

Volume 3, 2005

URI : https://id.erudit.org/iderudit/201752ar

DOI : https://doi.org/10.7202/201752ar

Aller au sommaire du numéro

Éditeur(s)

Société québécoise d'ethnologie

ISSN

1703-7433 (imprimé)

1916-7350 (numérique)

Découvrir la revue

Citer ce document

Gervais, J. (2005). Centre franco-ontarien de folklore. Rabaska, 3, 221-222.

https://doi.org/10.7202/201752ar

Ce document est protégé par la loi sur le droit d'auteur. L'utilisation des services d'Érudit (y compris la reproduction) est assujettie à sa politique d'utilisation que vous pouvez consulter en ligne.

https://apropos.erudit.org/fr/usagers/politique-dutilisation/
Cet article est diffusé et préservé par Érudit.

Érudit est un consortium interuniversitaire sans but lucratif composé de l’Université de Montréal, l'Université Laval et l'Université du Québec à Montréal. Il a pour mission la promotion et la valorisation de la recherche. https://www.erudit.org/fr/ 
Centre franco-ontarien de folklore 1169, rue Dollard Sudbury (Ontario) P4A 4G7
Téléphone: (705) 675-8986 Télécopieur: (705) 675-5809 Courriel: cfof@vianet.on.ca Toile: www.cfof.on.ca

\section{Étude de faisabilité}

Pour la première fois de son histoire, le CFof a tenu son assemblée générale annuelle à Ottawa, en juin dernier, manifestant de cette façon l'étendue de son mandat provincial ontarien. L'année 2004-2005 a été marquée par une grande étude de faisabilité intitulée «Plan de mise en valeur des ressources culturelles », préparée par la firme Gestion Initiative Développement GID de Québec. La deuxième version du rapport a été présentée au conseil d'administration et à ses partenaires en mars 2005. Ce rapport a été très bien reçu et a su générer beaucoup d'intérêt, surtout dans les médias. L'étude de GID, un projet à long terme, comprend deux volets : le réaménagement du musée de Sudbury et la mise en place d'un événement-spectacle.

\section{Le prix du patrimoine ontarois}

Le « Billochet du jongleur 2004 », prix annuel du patrimoine ontarois, a été décerné au conteur et écrivain d'Azilda, Ange-Émile Maheu. Il est le troisième lauréat à recevoir cette récompense qui signale « le mérite particulier d'une 
personne, d'un groupe de personnes, d'un organisme, d'une institution, d'une entreprise ou d'un événement qui a fait une contribution exceptionnelle pour la reconnaissance, la sauvegarde ou la mise en valeur du patrimoine oral franco-ontarien ». M. Maheu, originaire de la Beauce québécoise et arrivé en Ontario en 1950, écrit et interprète depuis 1995 les contes traditionnels entendus dans son enfance ; sous la plume de Mon oncle Émile, il tient aussi une chronique dans l'hebdomadaire de Sudbury, Le Voyageur, depuis déjà quatre ans. Il est l'auteur de quatre recueils mettant en valeur son patrimoine familial et il en a tiré deux disques.

\section{Conférence annuelle du patrimoine}

Le CFof a organisé le 5 février son douzième souper du patrimoine. Ce repasbénéfice annuel remporte de plus en plus de succès : les 128 participants ont entendu la conférence de Jacques Lortie et apprécié sa projection multimédia du spectacle « L'Écho d'un peuple », produit dans la région outaouaise par le groupe Francoscénie. C'est au cours de cette soirée qu'on a remis le prix du patrimoine ontarois.

\section{Expositions et activités}

Les expositions itinérantes du CFOF ont continué à circuler : " L'Influence du patrimoine oral sur l'œuvre de Maurice Gaudreault » était à Cap-Chat $(\mathrm{Qc})$, "Les Nombeurjacks du nord de l'Ontario », au Moulin des jésuites de Charlesbourg $(\mathrm{Qc})$, et « Passeur de mémoire », après un été à Cap-Chat, a passé l'automne à Owen Sound (Ontario). Le CFof publie un bulletin qui résume ses activités courantes : Le Billochet, $\mathrm{n}^{\text {os }} 34$ et 35, octobre 2004/avril 2005.

JoANNE GERVAIS 